\title{
Applying the Distributed Hydrological Model for Tropical Monsoon Basins by Using Earth Observation Data (Case Studies: Kone and Ba River Basins)
}

\author{
Phan Thi Thanh Hang \\ Department of Surface Water Resources, Institute of Geography, Vietnam Academy of Science and Technology, Hanoi, Vietnam \\ Email: Hangphanvn@yahoo.com
}

How to cite this paper: Hang, P. T. T. (2019). Applying the Distributed Hydrological Model for Tropical Monsoon Basins by Using Earth Observation Data (Case Studies: Kone and Ba River Basins). Journal of Geoscience and Environment Protection, 7, 23-37. https://doi.org/10.4236/gep.2019.71003

Received: November 21, 2018

Accepted: January 19, 2019

Published: January 22, 2019

Copyright () 2019 by author(s) and Scientific Research Publishing Inc. This work is licensed under the Creative Commons Attribution International License (CC BY 4.0).

http://creativecommons.org/licenses/by/4.0/

\section{(c) (i) Open Access}

\begin{abstract}
Due to the limitation of data sources, the application of Distributed Hydrological Models (DHMs) using earth observation data to research water resources is necessary. In this study, the BTOPMC (Block-wise use of TOPMODEL) model was applied for 2 basins in the tropical monsoon region. This is the first time that the land cover map of the CCI (Climate Change Initiative Land Cover Team) was prepared for input data instead of IGBP (International Geosphere-Biosphere Programme) land cover map as proposed in the demo version of the BTOPMC model. The calibration and validation results showed that the Nash-Sutcliffe coefficients for daily stream discharge were $77.5 \%$ and $68.7 \%$ at Cung Son station (Ba basin). The Nash-Sutcliffe coefficients for daily stream discharge were $79.4 \%$ and $69.0 \%$ at Binh Tuong station (Kone basin), respectively. Because of a stop in measuring the discharge at Binh Tuong station in 2007, this model was applied to simulate discharge during the period of 2008-2015. Furthermore, the effect of land cover on discharge at Cung Son station was considered. The annual discharge in 2010 at Cung Son decreased $8 \mathrm{~m}^{3} / \mathrm{s}$ in the comparison between two scenarios (land cover of 2000 and 2010). According to this result, it is possible to propose a wide application range of the DHMs model to the tropical monsoon river basins using earth observation data.
\end{abstract}

\section{Keywords}

Distributed Hydrological Model, Tropical Monsoon, Discharge, Land Cover, Earth Observation Data 


\section{Introduction}

In Vietnam, there are 2360 rivers with the length of over $10 \mathrm{~km}$, comprising eight large basins with the total area of more than $10,000 \mathrm{~km}^{2}$. Besides these eight basins, there are also 18 internal basins that have areas from 1000 to 10,000 $\mathrm{km}^{2}$ which are referred to as small basins. Most of these basins locate in the Central part of Vietnam where the distribution of water resources is very severe with flash floods, inundations in the rainy season and droughts in the dry season. In recent years, Vietnam has been facing an increasing frequency of natural disasters, particularly typhoons and droughts. Therefore, integrated water resources management is an urgent task for monsoon tropical countries like Vietnam. Due to limited data sources (only 70 discharge gauging stations in total), especially for small-ungauged basins, the application of hydrological models using earth observation data for the water balance calculation is of necessity.

Being the prime focus of hydrological research over the past decades, the simulation of rainfall-runoff relationship has resulted in an abundance of models that have been proposed. According to the process description, these models can be classified into three categories: metric, conceptual and physics-based models while based on the classification of spatial representation, they are either lumped or distributed. There exists no universal hydrological model that is applicable to all conditions of all basins and for various modeling purposes. However, the most promising developments in this respect are Distributed Hydrological Models (DHMs), especially ones that identify physically based on parameters. Distributed models in hydrology are physics-based models which are defined in terms of theoretically acceptable continuum equations. Distributed hydrological models can fulfill the necessity of describing basin heterogeneity, and assess the impact of natural as well as human induced changes. Furthermore, they enable researchers to take advantage of currently available satellite observations, which are rapidly improving in quality. Moreover, previous research that has utilized the application of DHMs to large basins, such as the Yellow River, Jinjiang and Mekong River basins obtained satisfactory results (Fu \& Chen, 2005; Zhou, Ishidaira, Hapuarachchi, Magome, Kiem, \& Takeuchi, 2006; Ishidaira, Ishikawa, Funada, \& Takeuchi, 2008; Sun, Wang, Li, Yao, \& Yu, 2014). Small basins in tropical monsoon region with limited observed data have not been considered. Moreover, the abundant source of earth observation data will be an effective source of input data for hydrological models.

In this study, the BTOPMC model was applied for 2 difference basin scales in the tropical monsoon region using earth observation data. Especially, the land cover map of the Climate Change Initiative Land Cover Team (CCI program, 2017) was prepared for data input instead of the land cover map of IGBP as proposed by the demo version of BTOPMC model.

\section{Study Area and Data}

The Kone and the Ba river basins are typical tropical monsoon basins (Figure 1). 


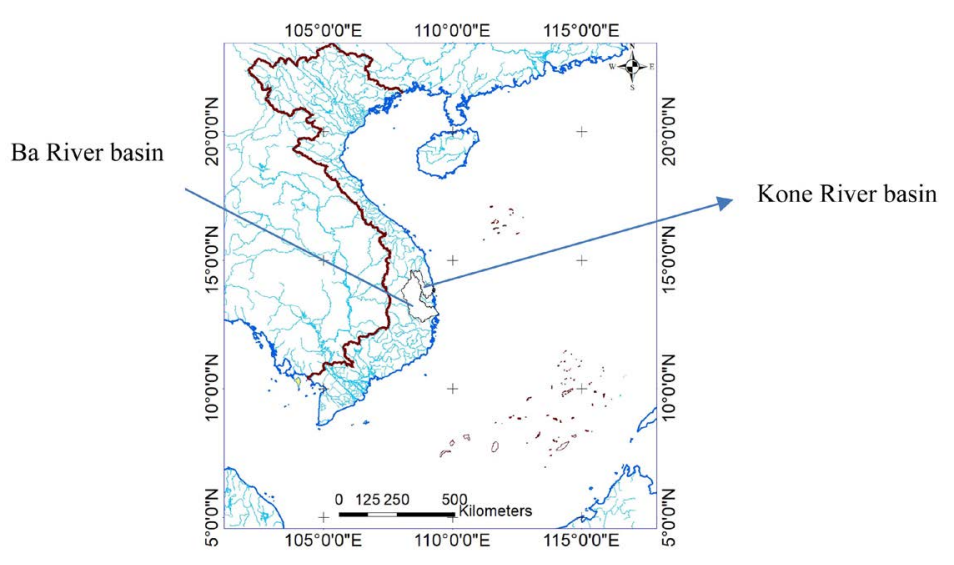

Figure 1. Locations of the Kone and the Ba river basins.

The Kone basin has an area of about $3640 \mathrm{~km}^{2}$, covering territories of An Lao, Vinh Thanh, Tay Son, Phu Cat, An Nhon, Van Canh, Tuy Phuoc districts in Qui Nhon city which belongs to Binh Dinh province, and K'Bang district which belongs to Gia Lai province. It locates in the west and south of Binh Dinh province at Central Vietnam from the latitude of $13.49^{\circ}$ to $14.62^{\circ} \mathrm{N}$ and from the longitude of $108.42^{\circ}$ to $109.32^{\circ} \mathrm{E}$ (Figure 2).

Surface water in this basin is plentiful but uneven in spatial and temporal distribution. The flood season in the Kone river is the latest in Vietnam (October to December) which accounts for $72.2 \%$ of total annual runoff in the country (Vietnam Meteorological and Hydrological Administration). High water volume is concentrated in 3 months, causing bad effect to the surface of the basin such as inundation. However, in the remaining 9 months (January to September) low flow season is very severe (Vietnam Meteorological and Hydrological Administration).

The $\mathrm{Ba}$ river basin has an area of about $13,900 \mathrm{~km}^{2}$, extending from $12.56^{\circ} \mathrm{N}$ to $14.62^{\circ} \mathrm{N}$ and from $108.00^{\circ} \mathrm{E}$ to $109.46^{\circ} \mathrm{E}$ (Figure 3). The Ba river basin is the largest basin in the South-Central region of Vietnam and locates in four provinces which are Kon Tum, Gia Lai, Dak Lak and Phu Yen (Vietnam Meteorological and Hydrological Administration). Over $71 \%$ of annual flow concentrates is in the flood season (from September to December), causing difficulties for water use in the basin (Vietnam Meteorological and Hydrological Administration).

Daily discharge data from 1979 to 2007 is obtained at Binh Tuong station in the Kone river basin (Figure 2). Data in 1998 is used for model calibration and data in 1999 is used for model validation. Daily discharge data from 1979 to 2016 is obtained at Cung Son station in the Ba river basin (Figure 3). Data in 2000 is used for model calibration and data in 2009 is used for model validation.

For this study, daily precipitation at gauged stations through the basin is obtained from 1979 to 2016 in both basins (the Kone basin Figure 2 and the Ba basin Figure 3). The distributed daily precipitation is obtained by applying the Thiessen polygon method. 


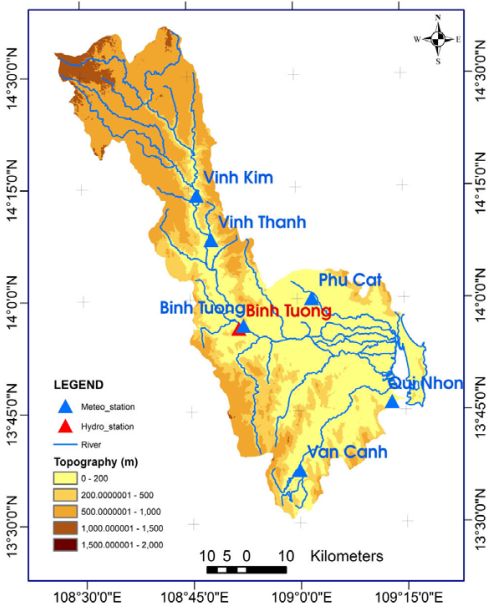

Figure 2. Location of meteorological stations and hydrological stations in the Kone river basin (Vietnam Meteorological and Hydrological Administration).

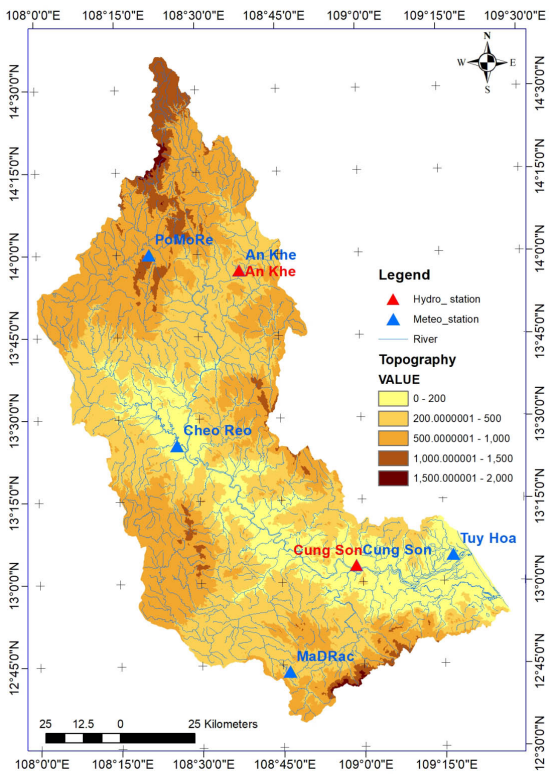

Figure 3. Location of meteorological stations and hydrological stations in the Ba river basin (Vietnam Meteorological and Hydrological Administration).

\section{Methodology}

The BTOPMC model is a physically based distributed hydrological model was developed by Takeuchi's Laboratory at the University of Yamanashi (Takeuchi, Tianqi, \& Ishidaira, 1999). This model divides the whole basin into many grid cells to account for spatial heterogeneity within the basin. At the same time, grid cells are grouped into several blocks in order to keep the model structure in a relatively simple manner.

The core module of $t$ the BTOPMC model consists of four sub-models namely topographic, parameter identification, runoff and flow routing. In this application, soil properties of all catchments are obtained by using the Food and Agriculture Organization (FAO, 2006) soil map and for Land cover map IGBP (In- 
ternational Geosphere Biosphere Program) will be used. The DEM (digital elevation model) and river network are generated from the USGS 30 arc second GTOPO30 data set. Spatial variation of precipitation is considered based on the Thiessen polygon method. Spatially distributed monthly average potential evapotranspiration is calculated by using the Shuttle Worth-Wallace (S-W) method. In the BTOPMC model, runoff generation is based upon the concepts of TOPMODEL which assumes that groundwater flow is driven by the surface topographic gradient, and flow routing is carried out using the Muskingum-Cunge method (Takeuchi, Tianqi, \& Ishidaira, 1999; Takeuchi, Hapuarachchi, Zhou, Ishidaira, \& Magome, 2008).

Five model parameters (Saturated transmissivity- $\mathrm{T}_{0}$, Decay factor of transmissivity $-\mathrm{m}$, Soil drying function parameter $-\alpha$, Manning's Roughness coefficient $-\mathrm{n}$ and Maximum root zone storage-Srmax) are calibrated by trial and error method. The result evaluation is based on the Nash-Sutcliffe coefficient (Nash \& Sutcliffe, 1970).

$$
N S E=1-\frac{\sum_{t=1}^{T}\left(Q_{s}^{t}-Q_{o}^{t}\right)^{2}}{\sum_{t=1}^{T}\left(Q_{o}^{t}-\overline{Q_{o}}\right)^{2}}
$$

where:

$Q_{s}$ is simulated discharge; $Q_{o}^{t}$ is observed discharge at time $t, \overline{Q_{o}}$ : the mean of observed discharges.

\section{Topographic data}

The BTOPMC model heavily depends on the DEM for the channel network extraction, sub-basin division and the soil-topographic index computation. The $\mathrm{S}-\mathrm{W}$ model also uses the DEM to correct some parameters. The DEM of the Kone and Ba river basins are downloaded from USGS GTOPO30 Elevation Data for GIS use. GTOPO30 is a global digital elevation model (DEM) resulting from a collaborative effort led by the staff at the U.S. Geological Survey's EROS Data Center in Sioux Falls, South Dakota. With the aim of meeting the needs for regional and continental scale topographic data of geospatial data user community, GTOPO30 is a global data set that was developed to cover the full extent of latitude from 90 degrees south to 90 degrees north, and the full extent of longitude from 180 degrees west to 180 degrees east. The name GTOPO30 is derived from the fact that elevations in GTOPO30 are regularly spaced at 30-arc seconds (approximately 1 kilometer). Since the horizontal grid spacing is 30 -arc seconds, dimensions of the DEM are 21,600 rows and 43,200 columns.

\section{Land cover}

The land cover is represented by the International Geosphere Biosphere Program (IGBP). IGBP classifies the global land cover into 17 types at $1 \mathrm{~km}$ resolution. However, the time series of consistent global land cover maps at $300 \mathrm{~m}$ spatial resolution on an annual basis from 1992 to 2015 (24 years) that shows 22 different types of global land cover classes were used in this study. This data is the product from the Climate Change Initiative Land Cover team, led by the 
Université catholique de Louvain (CCI program, 2017). The maps propose a legend that was based on the FAO/UNEP Land Cover Classification System in order to be compatible with previous products. This legend was converted to 17 types of land cover classes which are similar to IGBP's classification.

\section{Soil type}

The Food and Agriculture Organization (FAO)'s soil map is used in this study (Fao, 2006). There are altogether 7 soil textural classes in the Kone river basin and 8 soil textural classes in the Ba river basin, representing the content percentage of sand, silt and clay. However, when transferred into USDA soil classification, only four types remain: sandy loam, loam, sandy clay loam and clay. The FAO's classification is used for distributing to over the basin. The values of $T_{\text {o }}$ for sand, silt and clay are obtained by model calibration. The transferred USDA classes are used to assess the maximum soil moisture storage capacity of the root zone, $S_{\text {rmax }}$.

\section{NDVI data}

Based on the data of meteorological observation satellite NOAA of the United States, Normalized Difference Vegetation Index (NDVI) of resolution $1 \mathrm{~km}$, from April, 1997 to December, 2007 is produced by the Geospatial Information Authority of Japan. Moreover, NDVI of the space resolution $250 \mathrm{~m}$ is also made by this organization and has been being offered in the dataset since April, 2004 that the MODIS sensor of Advanced Earth Observing Satellite Terra of the United States observed since March, 2007. NDVI maps are collected from this source to prepare input data for the BTOPMC model (Geospatial Information Authority of Japan, 2012). The basin part of NDVI is clipped using the basin boundary and transferred into the Lambert Azimuthal Equal Area projection in Arc/Info software.

\section{Meteorological data}

Required meteorological data include precipitation, temperature, humidity, radiation and wind speed. The CRU (Climate Research Unit, University of East Anglia, 2002) TS 2.0 provides time series data of monthly mean temperature, diurnal temperature range, cloud cover and actual vapor pressure from 1901 to 2000 and mean monthly wind speed averaged in 1961-1990 for the globe at $0.5 \times$ 0.5 grids. The wind speed is measured at a majority of $10 \mathrm{~m}$ height. In construction of CRU TS 2.0, climatic variables are separated into two categories: primary and secondary variables. Regarding the data that is used in this study, primary variables are constructed directly from station observations, including mean temperature and diurnal temperature range. Secondary variables are constructed by merging the station observations including cloud cover and vapor pressure. For the synthetic data, the cloud cover is related to the diurnal temperature range using an empirical equation and the actual vapor pressure to the daily minimum temperature using a conceptual equation. The CRU data sets are extracted at the Kone and Ba river basins and transferred into the Lambert Azimuthal Equal Area projection at $8 \mathrm{~km}$ resolution without interpolation involvement. 


\section{Results and Discussion}

\subsection{Calibration and Validation}

River discharge data relative to the period of 1998 for Kone river and 2000 for $\mathrm{Ba}$ river was used to calibrate the model and other years for validating the model. In order to assess the performance of the model, the Nash-Sutcliffe efficiency coefficient (Nash \& Sutcliffe, 1970) was calculated. Nash-Sutcliffe coefficient reached $79.4 \%$ and $77.5 \%$ for Kone and Ba river basin, respectively, which implied that the model has a good performance in these areas. The calibration results are illustrated in Figure 4 for Kone river basin and in Figure 5 for Ba river basin. The overall model performance in the validation period as well as is rather good. Except for the peak values, which are slightly underestimated, the variation of the simulated discharge coincides with the observed discharge well from visual inspection.

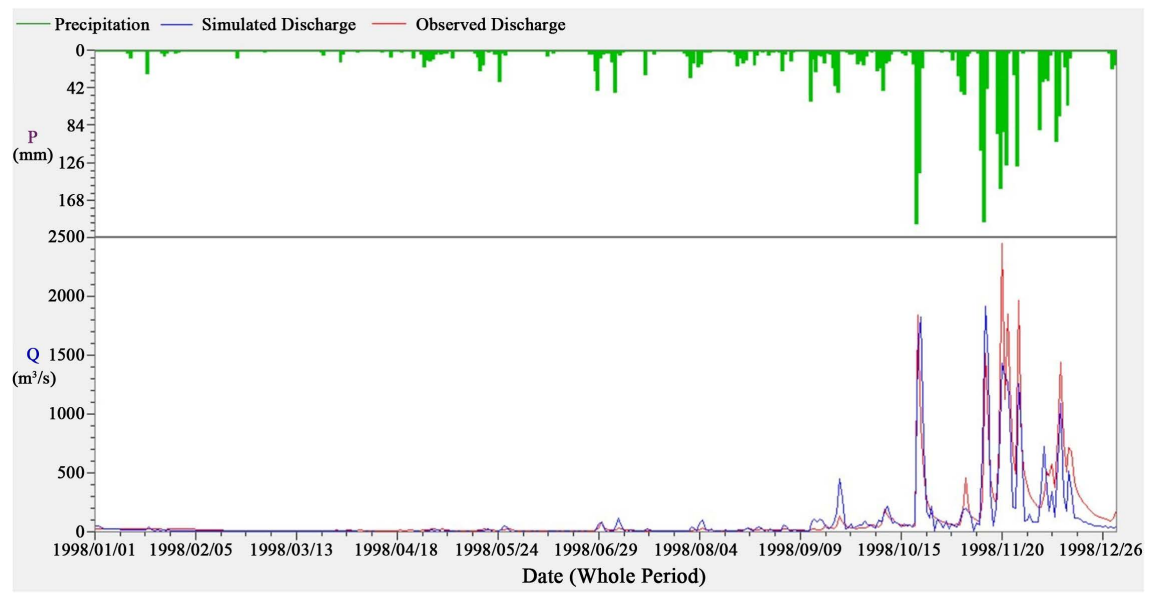

Figure 4. Simulated and observed discharge of 1998 at Binh Tuong station in the Kone river basin where $\mathrm{P}$ is observed precipitation in 1998, Q (blue line) is simulated discharge and Q (red line) is observed discharge by BTOPMC.

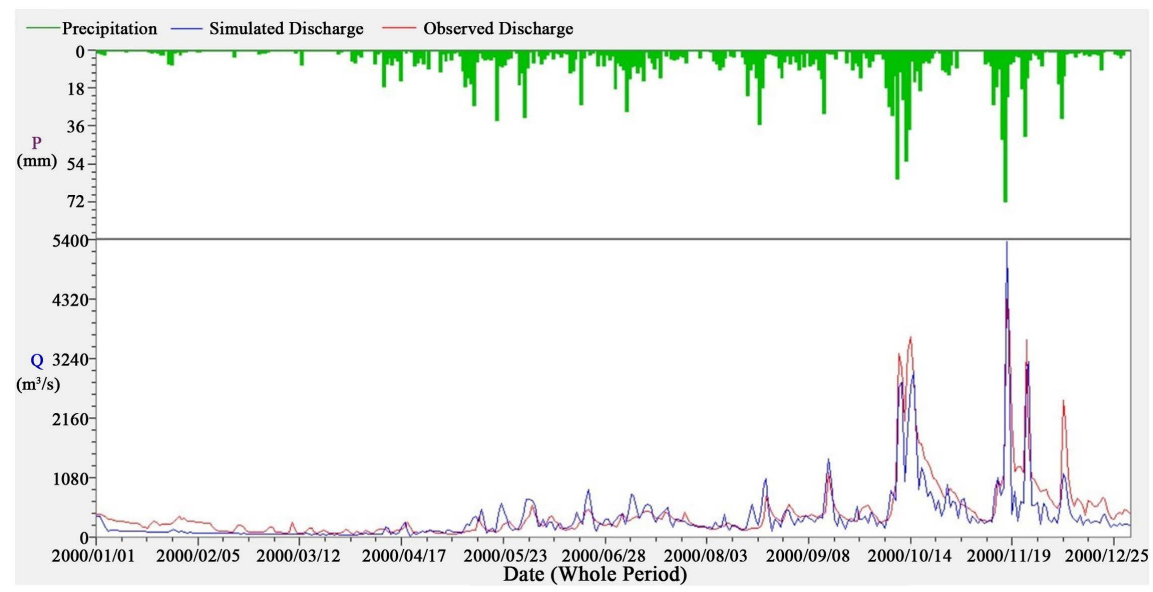

Figure 5. Simulated and observed discharge of 2000 at Cung Son station in the Ba river basin where $\mathrm{P}$ is observed precipitation in 2000, Q (blue line) is simulated discharge and Q (red line) is observed discharge by BTOPMC. 
As an example, Figure 6 shows one year of simulation time series of discharge in the Kone basin of 1999 compared to the observations while Figure 7 shows one year of simulation time series of discharge in the Ba basin of 2009 compared to the observations. The evolution of the simulated discharge is consistent with the observed discharge. This is also true for the other year of the period in two basins. However, there are some discrepancies in the timing of the flood events, which lead to differences between the observed and simulated discharge. Overall, the simulation is not as expected as compared to the calibration Nash-Sutcliffe coefficients only reached $69 \%$ at Binh Tuong station and $68.7 \%$ at Cung Son station (Table 1). This confirms that the model simulates the evolution of the discharge reasonably well, whereas the underestimated peak values which is reflected from relatively low Nash-Sutcliffe coefficients value. The calibration and validation results show that the BTOPMC model can reproduce the discharge, except for extreme discharge. Two parameter sets of the BTOPMC model at two stations in the $\mathrm{Ba}$ and Kone river basins are shown in Table 2.

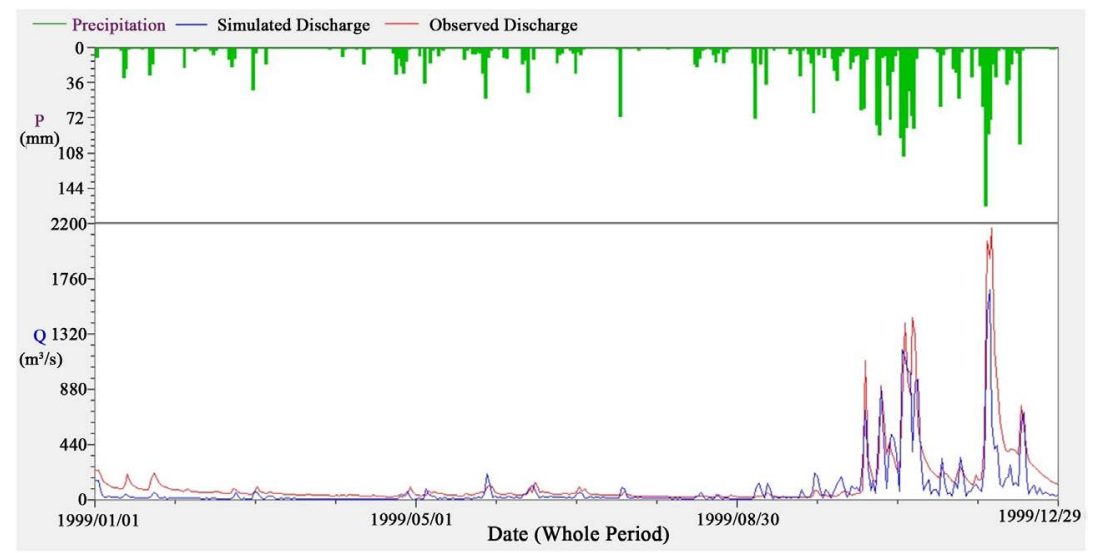

Figure 6. Simulated and observed discharge in 1999 at Binh Tuong station in the Kone river basin where P is observed precipitation in 1999, Q (blue line) is simulated discharge and Q (red line) is observed discharge by BTOPMC.

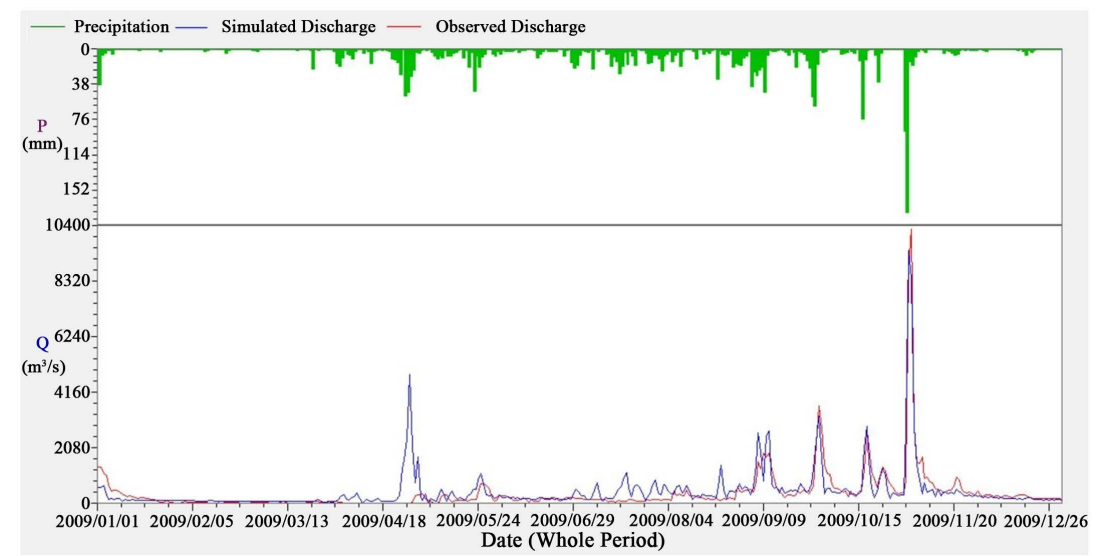

Figure 7. Simulated and observed discharge of 2009 at Cung Son station in the Ba river basin where P is observed precipitation in 2009, Q (blue line) is simulated discharge and $\mathrm{Q}$ (red line) is observed discharge by BTOPMC. 
Table 1. The BTOPMC model performance in 2 basins.

\begin{tabular}{cccccc}
\hline \multirow{2}{*}{ Station name } & \multirow{2}{*}{ Basin } & \multicolumn{2}{c}{ Calibration } & \multicolumn{2}{c}{ Validation } \\
\cline { 3 - 6 } & & Period & NSE & Period & NSE \\
\hline Binh Tuong & Kone & 1998 & $79.4 \%$ & 1999 & $69.0 \%$ \\
Cung Son & Ba & 2000 & $77.5 \%$ & 2009 & $68.7 \%$ \\
\hline
\end{tabular}

Table 2. Parameter sets of the BTOPMC model at two stations.

\begin{tabular}{ccccc}
\hline Parameter & Description & Unit & Binh Tuong & Cung Son \\
\hline $\mathrm{m}$ & Decay factor of transmissivity & - & 0.03 & 0.05 \\
$\mathrm{n}$ & Manning's Roughness coefficient & - & 0.01 & 0.02 \\
$\alpha$ & Soil drying function parameter & - & 3 & 4 \\
& Maximum root zone storage (Forest) & $\mathrm{m}$ & 0.06 & 0.08 \\
$\mathrm{~S}_{\text {rmax }}$ & Maximum root zone storage (Shrublands) & $\mathrm{m}$ & 0.04 & 0.06 \\
& Maximum root zone storage (Croplands) & $\mathrm{m}$ & 0.02 & 0.03 \\
$\mathrm{~T}_{0}$-clay & Saturated transmissivity Clay & $\mathrm{m}^{2} / \mathrm{h}$ & 8 & 10 \\
$\mathrm{~T}_{0}$-sand & Saturated transmissivity Sand & $\mathrm{m}^{2} / \mathrm{h}$ & 15 & 15 \\
$\mathrm{~T}_{0}$-silt & Saturated transmissivity Silt & $\mathrm{m}^{2} / \mathrm{h}$ & 12 & 12 \\
\hline
\end{tabular}

\subsection{Application of the Distributed Hydrological Model to Simulate Discharge in the Tropical Monsoon Basin}

The measurement of discharge data at Binh Tuong station in the Kone river basin was stopped in 2007. This paper presented the results of using the parameter set of Kone basin to simulate discharge at Binh Tuong station with observed precipitation data from 2008 to 2015 and land cover maps (CCI program, 2017). Simulated discharge is illustrated from Figure 8.

Those results are scientific basis to implement integrated water resources management for tropical monsoon basins, especially for ungauged small basins. Moreover, this model can be applied to predict discharge for tropical monsoon basins under climate change condition according to different scenarios.

\subsection{Effect of Land Cover Change on Discharge in Tropical Monsoon Basin}

Research on the effect of the land cover change on discharge has been done in many basins as well as by many models (Khoi \& Thom, 2015; Quyen, Lie, \& Loi, 2015; Tan, Ibrahim, Yusop, Duan, \& Ling, 2015; Deng, Zhang, Li, \& Pan, 2015; Wang, Wang, Ning, \& Hiroshi, 2018). This study used land cover maps that are available during 1992-2015 (CCI program, 2017) and applied the BTOPMC model to consider the effect of the land cover change on discharge in the $\mathrm{Ba}$ river basin. Land cover maps were chosen in the year of 2000 and 2010 (Figure 9). The changes of land cover in the Ba river basin concentrated in 

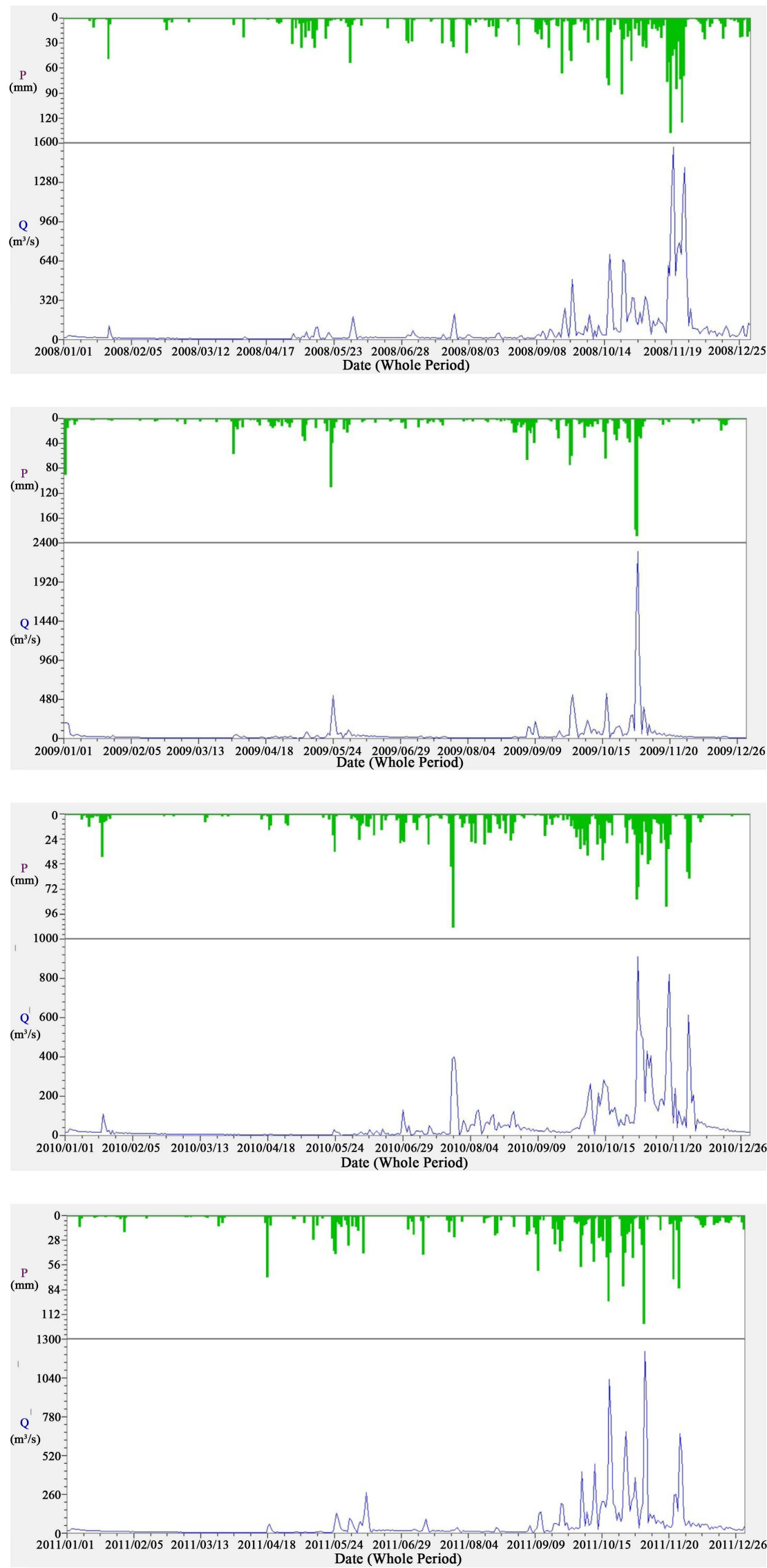

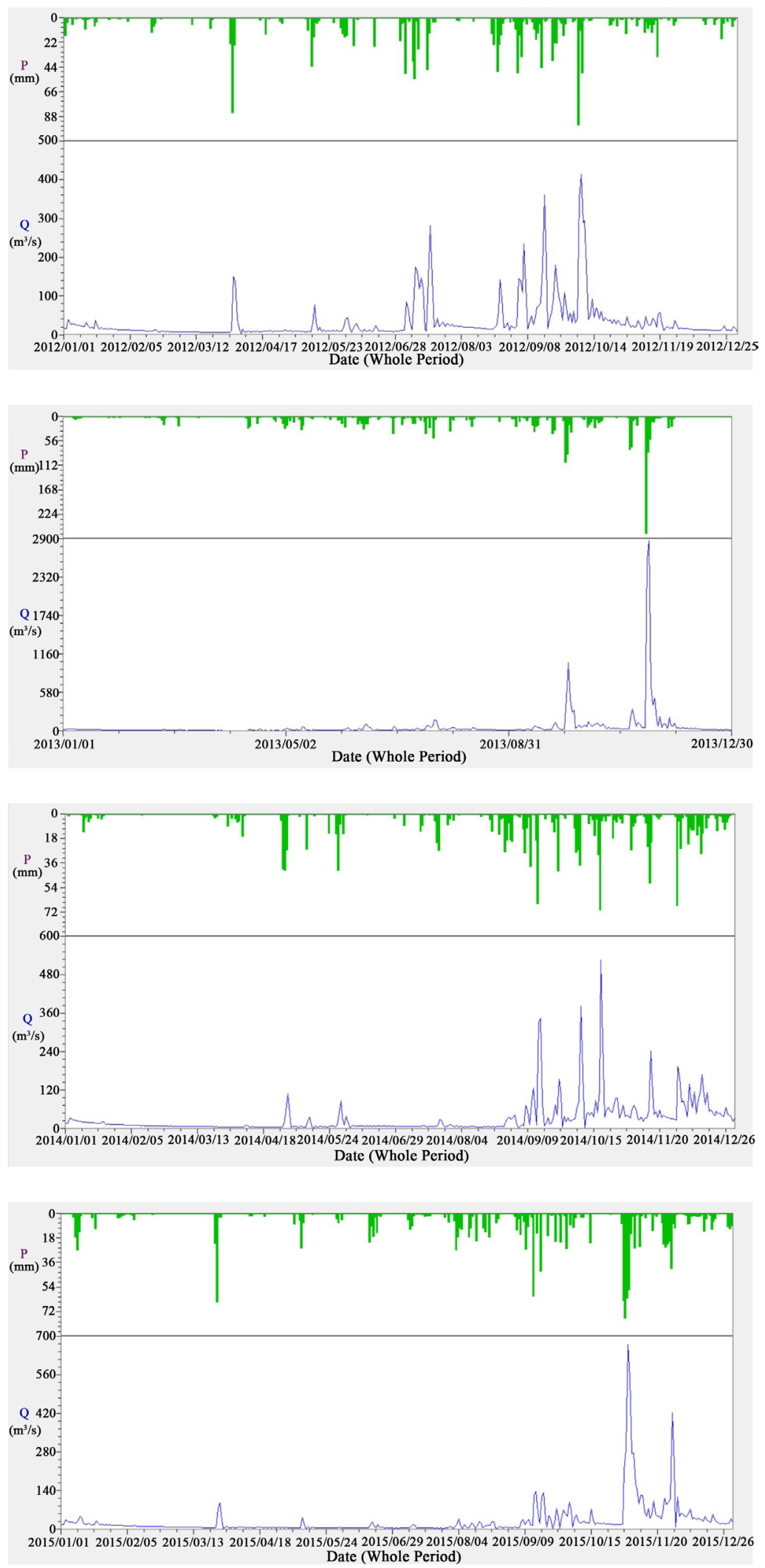

Figure 8. Simulated discharge in the period of 2008-2015 at Binh Tuong station in the Kone river basin where $\mathrm{P}$ is observed precipitation and $\mathrm{Q}$ is simulated discharge by BTOPMC model. 

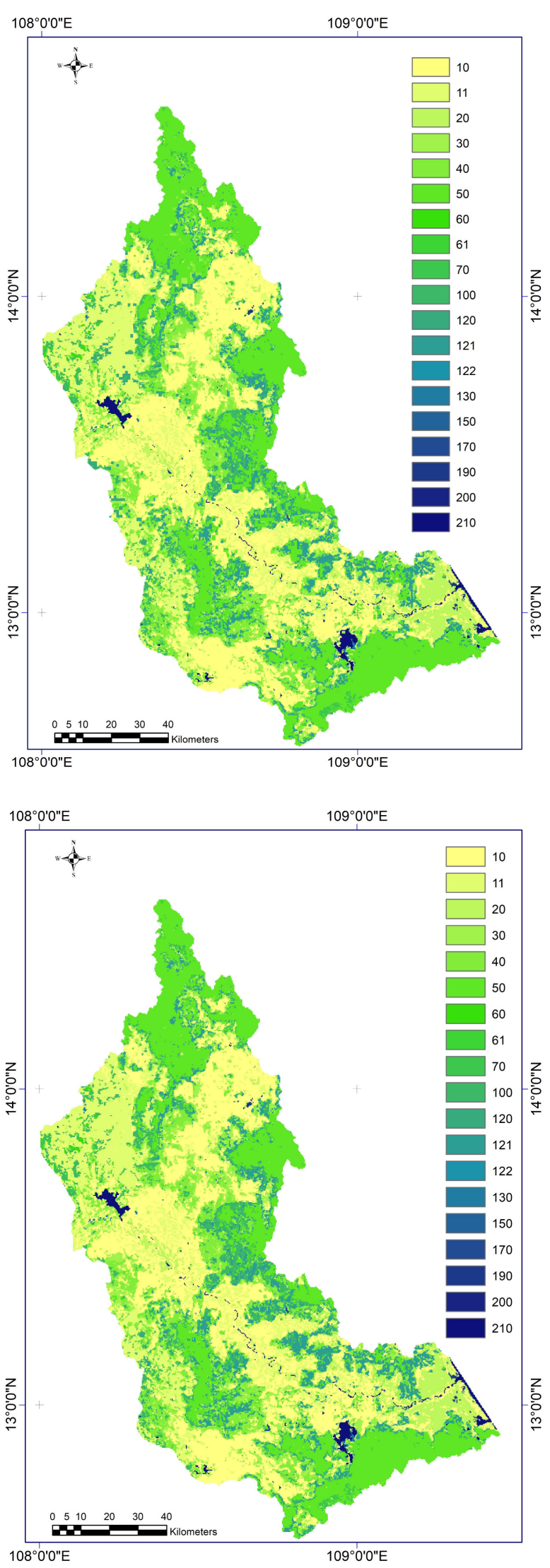

Figure 9. Land cover map of the Ba river basin in 2000 and 2010 (CCI program, 2017). 
the classes of 50 (Tree cover, broadleaved, evergreen, closed to open) and 120 (Shrubland). They increased from the year 2000 to the year 2010. Almost all of the other classes had the decreasing trend. The changes in land cover in the $\mathrm{Ba}$ river basin are illustrated in Figure 10. To estimate the effect of land cover changes on discharge in the Ba river basin, the approach of one factor at a time while keeping others constant is used. Climate data of 2010 and land cover map for 2010 is presented as baseline: Scenario 1. Land cover of 2000 and climate data of 2010 is presented as Scenario 2. Simulated results of discharge at Cung Son station in two scenarios by applying the BTOPMC model with parameter set are presented in Figure 11.

The discharge in 2010 at Cung Son decreased $8 \mathrm{~m}^{3} / \mathrm{s}$ in the comparison between two scenarios (land cover of 2000 and 2010). There is a decrease in discharge during the period of four months (from July to October) in the Ba river basin. These months presume the transitional months from dry season to flood season. The increase of 121 (evergreen shrubland), 100 (Mosaic tree and shrub/herbaceous cover), 40 (Mosaic natural vegetation (tree, shrub, herbaceous cover)/cropland, 30 (Mosaic cropland/natural vegetation (tree, shrub, herbaceous cover)), 20 (Cropland, irrigated or post-flooding), 11 (Herbaceous cover) and 10 (Cropland, rainfed) classes and the decrease of 120 (Shrubland) and 50 (Tree cover, broadleaved, evergreen, closed to open) classes are parts of reasons why discharge in 2010 decreased in transitional months in comparison to 2000 and 2010. The period of transition months is the period of water scarcity in

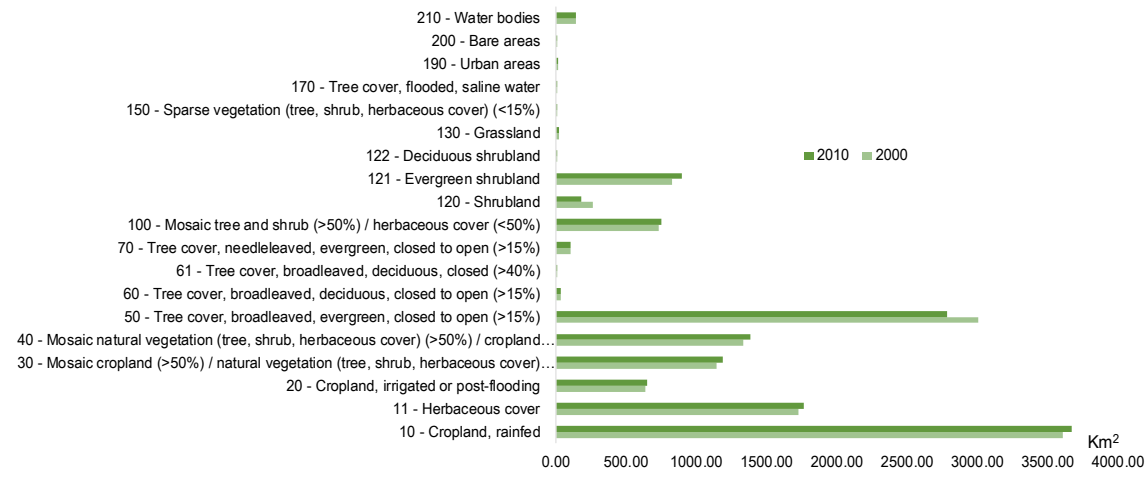

Figure 10. Changes of land cover in the Ba river basin duration 2000-2010.

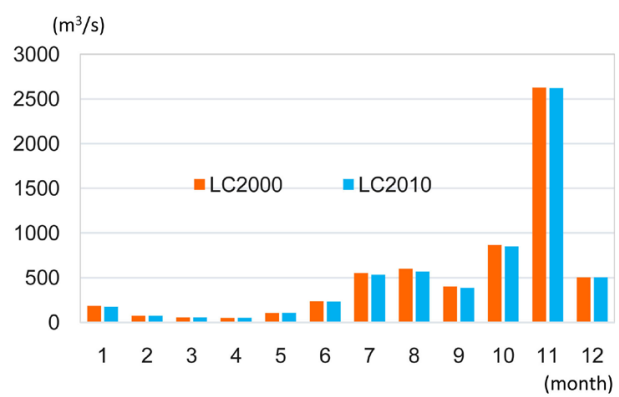

Figure 11. Simulated monthly discharge at Cung Son station in two scenarios (Baseline LC 2010 and Scenario 2-LC2000). 
tropical monsoon basins. The amount of precipitation in these periods is not enough to fill the evaporation loss and saturated soil moisture. Therefore, land cover plays an important part in water balance for tropical monsoon basins.

\section{Conclusion}

Integrated water resources management is an urgent task not only for Vietnam but also for other tropical monsoon countries. With limited data sources, especially for small-ungauged basins, the application of computational models using earth observation data for the water balance is necessary. This is the first-time that land cover map of the Université catholique de Louvain (CCI program, 2017) was used like input data in BTOPMC model. Using land cover map of CCI program in BTOPMC model can simulate discharge for ungauged small basins as well as consider the effect of land cover (land use) on river discharge.

Nash-Sutcliffe coefficients were $77.5 \%$ and $68.7 \%$ for calibration and validation at Cung Son station (Ba basin) and $79.4 \%$ and $69.0 \%$ at Binh Tuong station (Kone basin). Because of a stop in measuring the discharge at Binh Tuong in 2007, this model was applied to simulate discharge during the period of 2008-2015. Furthermore, the effect of land cover on discharge at Cung Son is considered. The discharge in 2010 at Cung Son decreased $8 \mathrm{~m}^{3} / \mathrm{s}$ in the comparison between two scenarios (land cover of 2000 and 2010).

The results of this research show that the BTOPMC (Distributed Hydrological Model) model using earth observation data can be applied to other basins in tropical monsoon region to simulate discharge especially for ungauged small basins. The effect of land cover on discharge was also considered in this research. Combination of the prediction model of land cover under climate change scenarios and the BTOPMC model is a task that will be implemented in the future to consider the effects of climate change on the water resources for tropical monsoon basins.

\section{Acknowledgements}

The author would like to thank anonymous reviewers for their helpful comments. The author also expresses her gratitude to Vietnam Academy of Science and Technology, the ESA CCI Land Cover project and GCOE program, University of Yamanashi in support of this research.

\section{Conflicts of Interest}

The author declares no conflicts of interest regarding the publication of this paper.

\section{References}

CCI Program (2017). Land Cover CCI. Version 2.0.

Deng, Z. M., Zhang, X., Li, D., \& Pan, G. Y. (2015). Simulation of Land Use/Land Cover Change and Its Effects on the Hydrological Characteristics of the Upper Reaches of the Hanjiang Basin. Environmental Earth Sciences, 73, 1119-1132. 
https://doi.org/10.1007/s12665-014-3465-5

FAO (2006). Global Soil Maps.

Fu, G. B., \& Chen, S. L. (2005). Geostatistical Analysis of Observed Streamflow and It Response to Precipitation and Temperature Changes in the Yellow River. Regional Hydrological Impacts of Climate Change-Hydroclimatic Variability. IAHS Publ., 296, 238-245.

Geospatial Information Authority of Japan (2012). NDVI-Data.

Ishidaira, H., Ishikawa, Y., Funada, S., \& Takeuchi, K. (2008). Estimating the Evolution of Vegetation Cover and Its Hydrological Impact in the Mekong River Basin in the 21st Century. Hydrological Processes, 22, 1395-1405. https://doi.org/10.1002/hyp.6948

Khoi, D. N., \& Thom, V. (2015). Impacts of Climate Variability and Land-Use Change on Hydrology in the Period 1981-2009 in the Central Highlands of Vietnam. Global NEST Journal, 17, 870-881. https://doi.org/10.30955/gnj.001706

Nash, J. E., \& Sutcliffe, J. V. (1970). River Flow Forecasting through Conceptual Models Part I-A Discussion of Principles. Journal of Hydrology, 10, 282-290. https://doi.org/10.1016/0022-1694(70)90255-6

Quyen, N. T. N., Lie, N. D., \& Loi, N. K. (2015). Effect of Land Use Change on Water Discharge in Srepok Watershed, Central Highland, Vietnam. International Soil and Water Conservation Research, 2, 74-86.

Sun, W. C., Wang, J., Li, Z. J., Yao, X. L., \& Yu, J. S. (2014). Influences of Climate Change on Water Resources Availability in Jinjiang Basin, China. The Scientific World Journal, 2014, Article ID 908349. https://doi.org/10.1155/2014/908349

Takeuchi, K., Hapuarachchi, P., Zhou, M., Ishidaira, H., \& Magome, J. (2008). A BTOP Model to Extend TOPMODEL for Distributed Hydrological Simulation of Large Basins. Hydrological Processes, 22, 3236-3251. https://doi.org/10.1002/hyp.6910

Takeuchi, K., Tianqi, A., \& Ishidaira, H. (1999). Introduction of Block-Wise of TOPMODEL and Muskingum-Cunge Method for Hydro-Environmental Simulation of Large Ungauged Basins. Hydrological Science Journal, 44, 633-646.

Tan, M. L., Ibrahim, A. L., Yusop, Z., Duan, Z., \& Ling, L. (2015). Impacts of Land-Use and Climate Variability on Hydrological Components in the Johor River Basin, Malaysia. Hydrological Sciences Journal, 60, 873-889.

University of East Anglia (2002). CRU CL v. 2.0.

Vietnam Meteorological and Hydrological Administration. Annual Observed Data.

Wang, J., Wang, H., Ning, S. W., \& Hiroshi, I. (2018). Predicting Future Land Cover Change and Its Impact on Streamflow and Sediment Load in a Trans-Boundary River Basin. Proceedings of the International Association of Hydrological Sciences, 379, 217-222. https://doi.org/10.5194/piahs-379-217-2018

Zhou, M. C., Ishidaira, H., Hapuarachchi, H. P., Magome, J., Kiem, A. S., \& Takeuchi, K. (2006). Estimating Potential Evapotranspiration Using Shuttleworth-Wallace Model and NOAA-AVHRR NDVI Data to Feed a Distributed Hydrological Model over the Mekong River Basin. Journal of Hydrology, 327, 151-173.

https://doi.org/10.1016/j.jhydrol.2005.11.013 